\title{
Turismo de mergulho: análise do comportamento de viagem dos mergulhadores brasileiros
}

Dive tourism: travel behavior of Brazilian divers

Turismo de buceo: análisis del comportamiento de viaje de los buceadores brasileños

http://dx.doi.org/10.18472/cvt.16n3.2016.1061

Raphael Younger Gonçalves Rowe 〈raphaelrowe@hotmail.com >

Instituto Federal de Educação, Ciência e Tecnologia de São Paulo (IFSP), São Paulo, SP, Brasil.

Glauber Eduardo de Oliveira Santos 〈 glauber.santos@usp.br >

Escola de Artes, Ciências e Humanidades da Universidade de São Paulo (EACH-USP), São Paulo, SP, Brasil.

CRONOLOGIA DO PROCESSO EDITORIAL

Recebimento do Artigo: 05-jul-2015

Aceite: 16-nov-2016

FORMATO PARA CITAÇÃO DESTE ARTIGO

ROWE, R. Y. G.; SANTOS, G. E. de O. Turismo de mergulho: análise do comportamento de viagem dos mergulhadores brasileiros. Caderno Virtual de Turismo. Rio de Janeiro, v. 16, n. 3, p. 61-75, dez. 2016.

\section{RESUMO}

$$
\text { REALIZAÇÃO }
$$

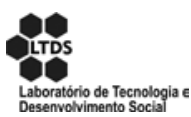

APOIO INSTITUCIONAL

COPPE
EDIÇÃO

IPITIR
PATROCÍNIO

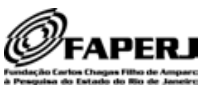


Atualmente, milhões de indivíduos praticam o mergulho autônomo recreativo em busca de prazer na observação e interação com a flora, fauna, geologia e arqueologia submarinas. A prática do mergulho autônomo motiva inúmeras viagens com pernoite fora do entorno habitual do mergulhador, dando origem ao chamado turismo de mergulho (autônomo). Esse segmento da atividade turística tem crescido substancialmente, oferecendo oportunidades e ameaças relevantes para empresas e destinos turísticos. Portanto, entender o comportamento de viagens dos turistas do segmento de mergulho autônomo pode contribuir para o desenvolvimento social e econômico, favorecendo também a preservação ambiental. O presente artigo tem como objetivo analisar o comportamento de viagem do turista de mergulho brasileiro. A análise, de abordagem quantitativa, foi feita a partir de questionários aplicados a 171 mergulhadores do país. Com base nesses dados e na revisão bibliográfica realizada, este trabalho traz sugestões para o aproveitamento do potencial turístico de destinos com vistas a otimizar os benefícios oferecidos pela atividade.

Palavras-chave: Turismo de mergulho. Mergulho autônomo. Demanda turística. Segmentos do mercado turístico.

\section{ABSTRACT}

Millions of people currently practice recreational scuba diving, searching for pleasure in the observation and interaction with underwater flora, fauna, geology and archeology. Scuba diving motivates numerous trips including overnight stays outside the usual environment of the diver, giving rise to the so-called scuba dive tourism. This segment of tourism has grown substantially, offering opportunities and threats for companies and tourism destinations. Therefore, understanding travel behavior of scuba dive tourists can contribute to social and economic development and to the promotion of environmental protection. This study aims to analyze the travel behavior of the Brazilian dive tourists. A quantitative analysis was conducted from 171 questionnaires applied to divers in the country. Based on these data and in the literature review, the paper provides suggestions for developing the tourism potential of destinations in order to maximize the benefits offered by the activity.

Keywords: Dive tourism. Scuba diving. Tourism demand. Tourism market segmentation.

\section{RESUMEN}

Actualmente, millones de personas practican el buceo recreativo en busca del placer de la observación e interacción con la flora, la fauna, la geología y la arqueología subacuática. La práctica del buceo motiva numerosos viajes con pernoctación fuera del entorno habitual del buceador, propiciando el surgimiento del turismo de buceo. Este segmento del turismo ha crecido sustancialmente, ofreciendo oportunidades y amenazas para las empresas y destinos turísticos. Por lo tanto, entender el comportamiento de viaje de los turistas de buceo puede contribuir al desarrollo social y económico, favoreciendo también la preservación del medio ambiente. Este artículo tiene como objetivo analizar el comportamiento de los viajes de los turistas buceadores de Brasil. El análisis, que tiene enfoque cuantitativo, se hizo a partir de cuestionarios aplicados a 171 buceadores en el país. Sobre la base de estos datos y la revisión de la literatura, este estudio ofrece sugerencias para el aprovechamiento de los potenciales de los destinos turísticos a fin de optimizar los beneficios ofrecidos por la actividad.

Palabras clave: Turismo de buceo. Demanda turística. Segmentación del Mercado turístico. 


\section{Introdução}

Mergulho é a atividade de submergir nas águas para explorar o mundo abaixo da linha de superfície. A atividade, que até o início do século XX era realizada de forma rudimentar, ganhou grande impulso a partir da difusão dos sistemas autônomos de respiração subaquática. $\mathrm{O}$ mergulho autônomo se tornou uma prática recreativa pelo menos desde os anos 1950 (GARROD, GÖSSLING, 2008). Atualmente, milhões de indivíduos praticam o mergulho exclusivamente pelo prazer de observar e interagir com a flora, fauna, geologia e arqueologia submarinas.

A prática do mergulho autônomo motiva inúmeras viagens com pernoite fora do entorno habitual do mergulhador, dando origem ao chamado turismo de mergulho (autônomo). Esse segmento da atividade turística tem crescido substancialmente (WORLD TourISM ORGANIZATION, 2007), oferecendo oportunidades e ameaças relevantes para empresas e destinos turísticos.

Portanto, entender o comportamento de viagens dos turistas do segmento de mergulho autônomo pode contribuir para o desenvolvimento social e econômico, favorecendo também a preservação ambiental. As informações disponíveis sobre tal comportamento em âmbito mundial são relativamente escassas, situação que se repete de forma ainda mais acentuada no Brasil. Dessa forma, o presente artigo tem como objetivo analisar o comportamento de viagem do turista de mergulho brasileiro. A análise de abordagem quantitativa foi feita a partir de questionários aplicados a 171 mergulhadores do país. Com base nesses dados e na revisão bibliográfica realizada, este trabalho traz sugestões de estratégias para o aproveitamento do potencial turístico de destinos com vistas a otimizar os benefícios oferecidos pela atividade.

\section{Turismo de mergulho}

O mergulho subaquático alcançou ampla viabilidade técnica apenas no século XX. De acordo com Larson (1959), o mergulho até cerca de 1930 era realizado essencialmente por meio de equipamentos que permitiam a submersão de indivíduos por determinado período, mas que impediam o livre movimento debaixo da água. Foi apenas a partir dos anos 1930 que começaram a surgir soluções para o mergulho autônomo que liberaram o indivíduo submerso de sua âncora na superfície, dando assim início à chamada era do mergulhador-nadador.

No final dos anos 1940 o sistema de circuito aberto de ar comprimido desenvolvido por Emile Gagnan e Jacques-Yves Cousteau, conhecido como Aqua Lung, passou a ser abertamente comercializado. A prática do mergulho subaquático deixou de ser exclusividade de inventores e militares, tornando-se acessível ao público em geral. A partir desse momento, o mundo subaquático, antes pouquíssimo explorado e amplamente misterioso, se revelou para a humanidade a partir de fotografias e vídeos. Jacques Cousteau teve uma participação central também nesse âmbito. Cousteau produziu mais de 100 filmes com imagens de mergulhos que tiveram grande repercussão mundial. O filme O Mundo Silencioso de 1956 chegou a ganhar a Palma de Ouro do Festival de Cannes e três outros filmes do diretor ganharam o Oscar (IMDB, 2015). Ao longo da história, outros vários filmes difundiram imagens submarinas, influenciando significativamente a demanda pelo mergulho, incluindo Homens Rãs (1951), Rochedos da Morte (1953), 20.000 Léguas Submarinas (1954), 007 Contra a Chantagem Atômica (1965), 007 Contra Octopussy (1983), Imensidão Azul (1988), A Pequena Sereia (1989), O Segredo do Abismo (1989) e Procurando Nemo (2003).

As informações e imagens impressionantes sobre esse ambiente pouco explorado, aliadas aos avanços tecnológicos, estimularam a prática com fins recreativos por pessoas comuns. Garrod e Gössling (2008, p. 4, tradução do autor) afirmam que "muitos mergulhadores mergulham pela simples diversão, para curti- 
rem a liberdade de estarem submersos, para verem o esplendor do ambiente submarino, para socializarem com outros praticantes e para depois contarem suas histórias". De acordo com Davis e Tisdell (1995), os principais motivos que levam pessoas a praticar o mergulho autônomo recreativo são:

- Busca por experiências próximas à natureza;

- Interesse na ecologia marinha;

- Interesse em outras características do ambiente submerso, como geologia e arqueologia;

- Imagem de ser um esporte diferenciado e especial;

- Prática de outros hobbies, como fotografia;

- Busca pelo sentimento de aventura e excitação;

- Simples busca pela experiência.

A partir de uma pesquisa qualitativa, Ince e Bowen (2011) identificaram os principais aspectos que satisfazem os mergulhadores recreativos. Entre os elementos objetivos se destacam a vida marinha, a visibilidade debaixo da água, os aspectos sociais, a flutuabilidade do mergulhador, os serviços disponíveis na embarcação, a segurança pessoal e os equipamentos específicos. Aspectos subjetivos relevantes para a satisfação dos mergulhadores incluem a sensação de contato com a natureza, a fuga do cotidiano, o contato com o desconhecido e a percepção de desenvolvimento de habilidades.

Szuster, Needham e McClure (2011) mostram que os mergulhadores gostam da sensação de exclusividade na exploração dos ambientes submersos. Os praticantes dessa atividade preferem que apenas seus próprios grupos de colegas estejam no local visitado, fato que oferece uma maior sensação de proximidade com a natureza. Schuhmann et al. (2013) estimam que os mergulhadores em Barbados e em Tobago estariam dispostos a pagar cerca US\$ 4,51 para evitar encontros debaixo da água com outros grupos de mergulhadores. Vaske et al. (2013) estimam que o encontro com mais de 25 pessoas no ponto de mergulho é inaceitável por parte dos mergulhadores.

Ainda que acessível a pessoas comuns, a prática do mergulho exige conhecimentos técnicos e habilidades específicas. Mergulhar sem os devidos cuidados traz grandes riscos à saúde e pode levar à morte. Vann e Lang (2010) reportam taxas de mortalidade entre 14,4 e 16,4 por 100.000 pessoas, valores similares aos da prática de outras atividades, como transporte em automóveis ou corrida a pé. Principalmente em virtude desses riscos, diferentes entidades passaram a oferecer cursos e certificações de mergulho. A enciclopédia Wikipedia (2015) lista mais de 140 organizações certificadoras de mergulhadores. A mais importante entidade desse tipo é a Professional Association of Diving Instructors (PADI). Criada nos Estados Unidos em 1966, a PADI já certificou mais de 23 milhões de mergulhadores em cerca de 200 países (PADI, 2015b).

Uma vez que o mergulho autônomo é uma atividade realizada em locais específicos, é comum que os praticantes se desloquem de seus entornos habituais para mergulhar. Muitas vezes os deslocamentos realizados são grandes e acabam exigindo pernoites fora de casa. Surge aí o turismo de mergulho, ou seja, a prática de viagens turísticas com o objetivo principal de praticar essa atividade (WORLD TourISM ORGANIZATION, 2007).

Os mergulhadores recreativos usualmente têm interesse em mergulhar em locais diferentes, ainda não explorados por eles próprios anteriormente, a fim de conhecer pontos de mergulho com características distintas, fotografar novos elementos, ter experiências novas e mais excitantes. Pode-se dizer que os mergulhadores tendem a apresentar um perfil que seria classificado por Plog como alocêntrico (PLOG, 2001) ou aventureiro (PLOG, 2002). Assim, o turismo de mergulho autônomo não existe apenas como meio 
para que os mergulhadores acessem pontos viáveis para a prática desse esporte. Os pontos mais próximos ou convenientes nem sempre são os escolhidos como destino. Os locais mais atraentes, com características mais interessantes, melhor clima e ainda desconhecidos estão frequentemente afastados da residência dos mergulhadores (QUEIROZ NETO, 2012).

A busca individual e coletiva por novos locais de mergulho levou à exploração de milhares de pontos ao redor do mundo. O mergulho motivou o turismo em locais pouco visitados por outros tipos de turistas, incluindo ilhas isoladas e partes inabitadas das costas continentais. O fluxo de turistas em alguns desses destinos se tornou consideravelmente grande, favorecendo o surgimento de infraestrutura e o desenvolvimento de outros segmentos do turismo. Outros locais permaneceram desconhecidos do público não mergulhador. Conforme ressalta a Organização Mundial do Turismo - OMT (WORLD TourISM ORGANIZATION, 2007), a atratividade do destino turístico para esse segmento "está quase exclusivamente relacionada à prática desse esporte e, em menor grau, com a qualidade da hospedagem ou dos atrativos em terra". Uma breve análise de um guia mundial de destinos de mergulho, como aquele da série Eyewitness Companions (HALLS, KRESTOVNIKOFF, 2006), revela que a lista de locais recomendados se diferencia consideravelmente das listas mais usuais de destinos turísticos comuns sugeridos pelos guias generalistas. Essa característica dos destinos de mergulho é confirmada também a partir da análise da localização dos 10 melhores pontos do mundo para a prática do mergulho autônomo segundo o Scuba Travel (2015):

1. Yongala, Cape Bowling Green, Queensland, Austrália

2. Thistlegorm, Parque Nacional Ras Muhammad, Mar Vermelho, Egito

3. Blue Corner Wall, Palau, Micronésia

4. Barracuda Point, Ilha Sipadan, Malásia

5. Shark and Yoland Reef, Parque Nacional Ras Muhammad, Mar Vermelho, Egito

6. Manta Ray Night Dive, Kailua Kona, Havaí, Estados Unidos

7. Navy Pier, Exmouth, Western Australia, Austrália

8. Big Brother, Mar Vermelho, Egito

9. Great Blue Hole, Belize

10. Liberty, Bali, Indonésia

Cabe notar que o único ponto de mergulho brasileiro incluído na lista dos 100 melhores do mundo segundo o Scuba Travel (2015) é Pedras Secas em Fernando de Noronha (PE). Esse também é o único ponto de mergulho brasileiro citado entre os 50 melhores do mundo segundo a SportDiver (2015). Entre os 50 melhores pontos de mergulho do mundo citados pela CNN, nenhum fica no Brasil (BREMMER, 2012). O mesmo ocorre com os 100 melhores pontos eleitos pela Scuba Diving (2015). No país, de acordo com o Ministério do Turismo (2005), alguns dos principais destinos de turismo de mergulho são Fortaleza (CE), Maracajaú (RN), Natal (RN), João Pessoa (PB), Fernando de Noronha (PE), Recife (PE), Porto de Galinhas (PE), Serrambi (PE), Salvador (BA), Caravelas (BA), Vitória (ES), Guarapari (ES), Búzios (RJ), Cabo Frio (RJ), Arraial do Cabo (RJ), Rio de Janeiro (RJ), Angra dos Reis (RJ), Paraty (RJ), Ubatuba (SP), Ilhabela (SP), Santos (SP), Bombinhas (SC), Florianópolis (SC), Bonito (MS) e Rio Quente (GO).

A organização do mercado de turismo de mergulho autônomo é bastante complexa e desenvolvida na atualidade (GRAVER, 2010). Nas grandes e médias cidades é possível encontrar empresas que prestam serviços de agenciamento de viagens especiais para a prática do mergulho autônomo. Algumas dessas 
empresas são efetivamente agências de viagens, sejam elas especializadas em turismo de mergulho ou agências comuns que exploram diversos segmentos do mercado, entre eles o de turismo de mergulho. $\mathrm{O}$ agenciamento e operação de viagens especiais também é frequentemente feito por escolas de mergulho. Nesses casos o serviço de agenciamento é complementar aos cursos e certificações ofertadas pela empresa, ainda que muitas vezes constituam uma parcela significativa da receita.

Nos destinos, usualmente, existem empresas especializadas em operações de mergulho, prestando serviços de aluguel de equipamentos, transporte em barcos, instrução e guiamento subaquático. Em alguns destinos também existem resorts de mergulho, empresas que prestam conjuntamente serviços de hospedagem e operações de mergulho, além de usualmente oferecerem estruturas de apoio, tais como lojas de equipamentos, centros de formação de mergulhadores, salas para tratamento de fotografias e outros. Por fim, destacam-se ainda os navios de live-aboard, isto é, embarcações de cruzeiro que oferecem essencialmente hospedagem e operações de mergulho, além de eventualmente incluírem outras comodidades especiais.

A associação do mergulho autônomo com a questão ambiental é particularmente relevante. De um lado, a maioria dos mergulhadores busca um contato próximo com o ambiente natural preservado. Quanto mais experientes, mais preocupados e cuidadosos com o meio ambiente submarino são os mergulhadores (COTTRELL, MEISEL, 2003; ONG, MUSA, 2012). O mergulho leva muitos dos envolvidos com a atividade a se tornarem defensores da natureza e militantes da ecologia (TOWNSEND, 2008). A condição dos pontos de mergulho constitui uma questão fundamental para o desenvolvimento dos destinos. $\mathrm{O}$ mergulho tem inclusive favorecido a criação de áreas de proteção ambiental ao redor do planeta, por vezes sendo o principal motivo da delimitação destas. Além disso, o mergulho muitas vezes é fonte de receita para áreas de proteção ambiental, colaborando com a disponibilização de recursos para a preservação do meio ambiente (ASAFU-ADJAYE; TAPSUWAN, 2008; DE GROOT; BUSH, 2010; STOECKL et al., 2010).

Por outro lado, a própria prática do mergulho degrada o ambiente submarino. Quanto maior a visitação, maiores são os impactos ambientais negativos, como a quebra ou abrasão de corais, a suspensão de sedimentos e as alterações no comportamento da fauna. Diversas formas de gestão desses impactos têm sido desenvolvidas (UYARRA; WATKINSON; COTE, 2009), mas a aplicação dessas estratégias ainda é problemática. Garrod e Gössling (2008) destacam também o potencial de contribuição do mergulho para a mudança climática, já que a atividade frequentemente envolve o transporte de alto consumo energético para acessar os mais afastados destinos de viagem e os pontos de mergulho mais isolados.

Segundo a OMT (2001), o turista de mergulho é geralmente jovem e tem renda acima da média. Garrod e Gössling (2008) citam vários estudos indicando que os turistas mergulhadores geralmente têm entre 30 e 50 anos, justificando que essa tendência tem relação com a disponibilidade de renda e saúde física. A renda elevada também é comprovada por uma série de pesquisas (DITTON et al., 2002; GÖSSLING et al., 2008; TABATA, 1992). Mergulhadores tendem ainda a ter nível de escolaridade relativamente elevado (CATER; CATER, 2001; DITTON et al., 2002; MUSA; KADIR; LEE, 2006; TABATA, 1992). A maioria dos mergulhadores são do sexo masculino (GARROD; GÖSSLING, 2008; MUNDET; RIBERA, 2001; O'NEILL et al., 2000; PADI, 2015b). A OMT (WORLD TourISM ORGANIZATION, 2007) afirma ainda que esse público viaja ao exterior com frequência para praticar a atividade. Boa parte dos turistas desse segmento faz viagens em grupos exclusivos para mergulhadores. Turistas de mergulho em geral são experientes tanto no mergulho (COTTRELL; MEISEL, 2003; MUNDET; RIBERA, 2001; MUSA; KADIR; LEE, 2006) quanto no turismo (MUNDET; RIBERA, 2001; THAILING; DITTON, 2003), tendo mergulhado mais vezes e viajado mais que outros públicos.

As informações disponíveis sobre o segmento de turismo de mergulho autônomo no Brasil são escassas e incompletas. A PADI Brasil atualmente forma cerca de 17 mil mergulhadores anualmente, conta- 
bilizando um total de mais de 180 mil mergulhadores certificados no país a partir de seus 86 centros de mergulho credenciados (PADI, 2015a). As tendências de idade reduzida, renda e escolaridade elevadas e sexo masculino observadas no âmbito mundial também se reproduzem no Brasil (PADI, 2015a). De acordo com o Ministério do Turismo (2005), em 2005 haviam no Brasil 65 mil indivíduos que realizavam ao menos 12 mergulhos por ano e o turismo de mergulho movimentava anualmente R 26 milhões.

\section{Método e resultados}

Informações sobre o perfil e o comportamento dos turistas de mergulho brasileiros foram levantadas por meio de uma amostra não probabilística. A seleção dos participantes se deu a partir de comunicados veiculados em comunidades de mergulhadores existentes no Facebook e de contatos pessoais e institucionais dos pesquisadores envolvidos no trabalho. Os potenciais participantes receberam um link para o questionário disponibilizado através do sistema Google Drive. A coleta foi realizada durante os meses de outubro e novembro de 2014 e foram obtidas 171 respostas.

A maior parte $(78,4 \%)$ dos entrevistados eram homens e com idade entre 30 e 50 anos $(64,9 \%)$. Essa é uma participação relativamente grande, já que os indivíduos nessa faixa etária correspondem a apenas $28,6 \%$ da população brasileira (IBGE, 2015). Contudo, as faixas etárias de 26 a 30 e de 50 a 60 anos também apresentaram frequências significativas (15,2\% e 12,3\%, respectivamente). Apenas 4,7\% dos entrevistados tinham 25 anos ou menos e apenas 2,9\% tinham mais de 60 anos. A pesquisa apontou também que os turistas de mergulho apresentam nível relativamente alto de escolaridade, sendo que 53,2\% possuem pós-graduação e outros $31,6 \%$ têm ensino superior completo. O total de $84,8 \%$ de mergulhadores que possuem ao menos nível superior contrasta fortemente com a participação de 7,1\% desse público na população brasileira em geral (IBGE, 2015). O nível de renda familiar mensal também se revelou elevado, já que 37,1\% têm renda superior a 15 salários mínimos e, ao todo, 71,8\% têm renda superior a 8 salários mínimos. No total da população brasileira com 10 anos ou mais, a participação de pessoas com rendimento acima de 15 salários mínimos é de apenas 1,4\% (IBGE, 2015). A maior parte dos entrevistados é dos estados de São Paulo (49,7\%) e Rio de Janeiro (23,4\%). As regiões Sul e Nordeste respondem cada uma por $5,3 \%$ dos entrevistados.

Os participantes da pesquisa são relativamente experientes na atividade de mergulho. A maioria $(65,5 \%)$ pratica mergulho há mais de 5 anos e apenas $8,8 \%$ começaram a mergulhar há menos de 1 ano. Mais da metade dos entrevistados (53,8\%) já realizaram mais de 100 mergulhos e 17,5\% mergulharam entre 41 e 100 vezes. Apenas 15,8\% dos entrevistados têm certificação básica, sendo frequentes os portes de certificações superiores, como avançado $(29,2 \%)$, mergulhador de resgate $(16,4 \%)$ e dive master ${ }^{1}(35,1 \%)$. Dois terços dos participantes da pesquisa (66,7\%) têm equipamento próprio completo para o mergulho e 21,1\% têm equipamento parcial, sendo que apenas $12,3 \%$ não têm equipamento próprio ou têm apenas os itens básicos (nadadeira, máscara ou snorkel). As modalidades de mergulho mais praticadas são o mergulho noturno (84,8\% dos entrevistados já praticaram), profundo (82,5\%) e em naufrágio (73,7\%). Duas modalidades menos frequentes também merecem destaque: mergulho em caverna $(31,0 \%)$ e alimentação de tubarões $(22,8 \%)$.

A atividade de mergulho tem forte associação com as relações sociais dos indivíduos. A forte interação social relacionada ao mergulho se revela por meio das redes de amizades formadas. Mais da metade dos entrevistados (55,6\%) afirmaram que têm mais de 10 amigos mergulhadores. Além disso, grande parte dos mergulhadores entrevistados $(42,7 \%)$ afirmou que suas principais influências para a prática dessa

1 Significa “líder de mergulho". 
atividade foram amigos e parentes. Contudo, deve-se destacar que a influência da mídia na motivação dos mergulhadores também é substancial, já que 19,3\% dos entrevistados afirmaram que suas principais influências para iniciar essa prática foram notícias e reportagens, ao passo que $14,6 \%$ destacaram a influência dos filmes.

A prática do mergulho em viagens não motivadas majoritariamente por outras questões que não o próprio mergulho é relativamente rara. Boa parte dos entrevistados $(29,8 \%)$ afirmou nunca ter mergulhado em viagens dessa natureza. Apenas 19,3\% afirmaram ter realizado algum mergulho em mais de 5 viagens feitas com outras motivações. Esses percentuais podem ser considerados pequenos se comparados aos números de viagens feitas especificamente para mergulhar, conforme apresentado mais adiante. Além disso, mais da metade dos entrevistados (56,7\%) afirmou que mesmo nessas viagens motivadas por outras questões, os mergulhos sempre fizeram parte do plano e tiveram influência na escolha do destino. Cabe destacar que, nessas viagens, a contratação dos serviços de mergulho foi feita majoritariamente de forma ativa, seja através da busca presencial por uma operadora de mergulho no destino $(55,0 \%)$ ou por meio da reserva antecipada dos serviços (40,4\%). Apenas 4,7\% dos entrevistados afirmam que nessas viagens seus mergulhos foram contratados a partir do contato de promotores de vendas.

A realização de viagens motivadas majoritariamente pela prática do mergulho é bastante frequente. Apenas 2,3\% dos entrevistados nunca realizaram qualquer viagem para mergulhar. Em particular, 82,5\% já realizaram alguma viagem de um dia sem pernoite e $95,3 \%$ já fizeram alguma viagem com pernoite. Além disso, 19,3\% dos indivíduos fizeram mais de 50 viagens de um dia e 22,2\% fizeram mais de 50 viagens com pernoite. As distribuições dos entrevistados segundo os números de viagens de cada categoria realizadas com a motivação principal de mergulhar são apresentadas nas figuras 1 e 2 .

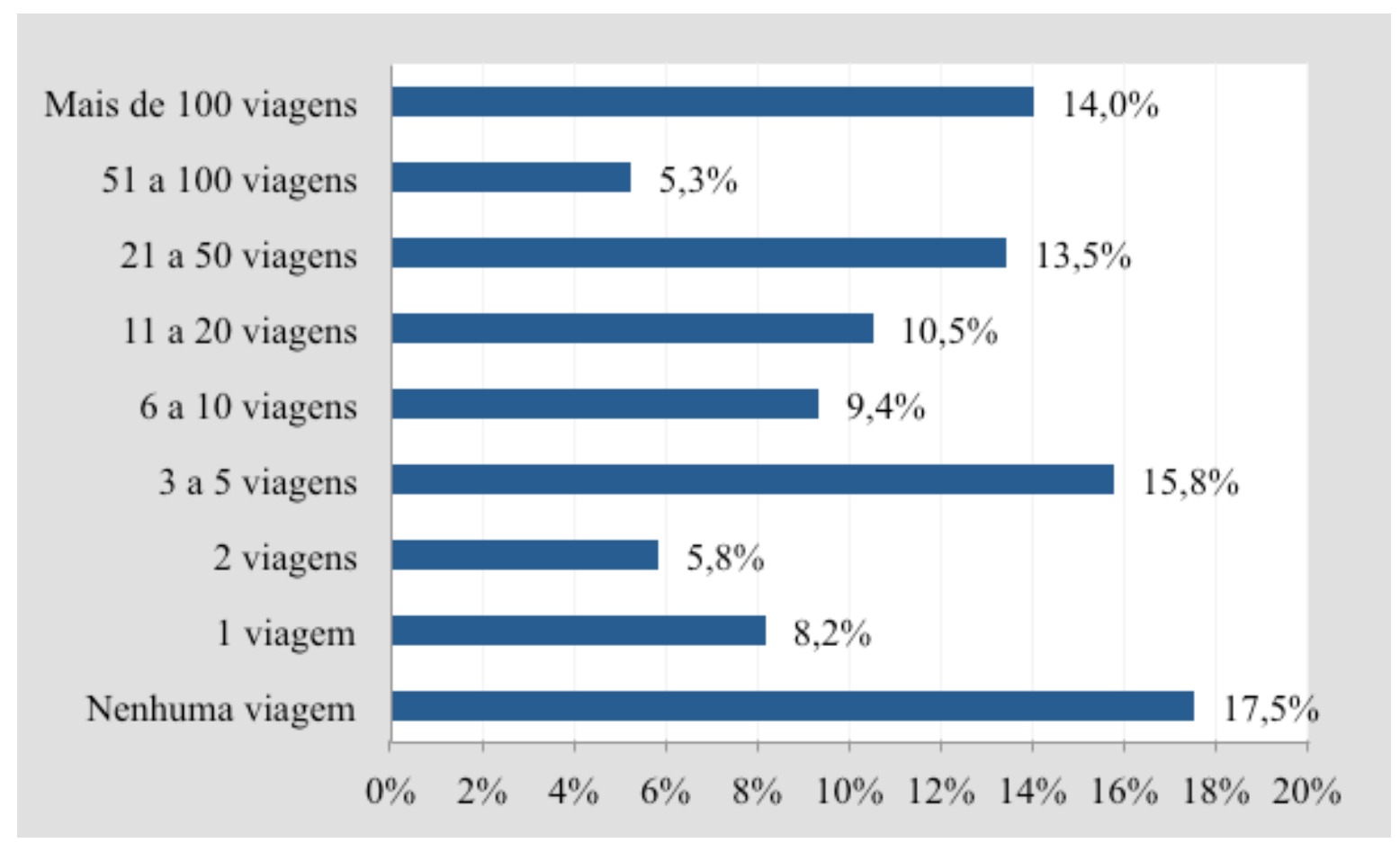

Figura 1 - Distribuição dos entrevistados pelo número de viagens de um dia realizadas motivadas pelo mergulho

Fonte: Elaboração própria. 


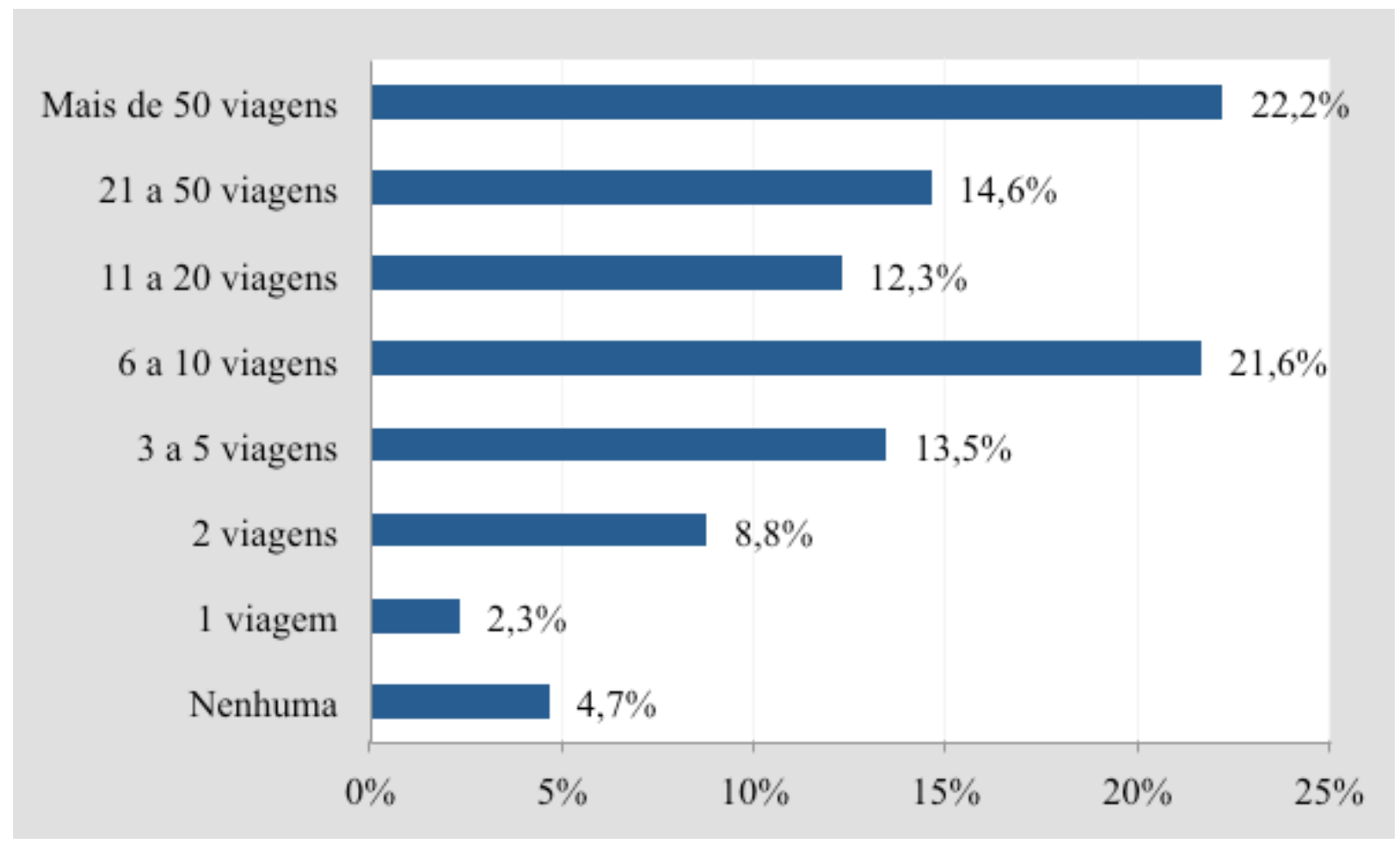
Figura 2 - Distribuição dos entrevistados pelo número de viagens com pernoite realizadas
motivadas pelo mergulho

Fonte: Elaboração própria.

Muitas viagens para mergulho são organizadas por meio de escolas de mergulho ou operadoras especializadas. Quase metade (49,7\%) dos entrevistados afirmou que a maioria de suas viagens com pernoite voltadas à prática do mergulho foi organizada dessa forma. Contudo, a organização independente por parte do próprio indivíduo também é frequente, sendo que 47,9\% afirmaram ser essa a alternativa mais comum para suas viagens. As viagens para mergulho organizadas por meio de pacotes turísticos comuns são muito pouco frequentes. Apenas 2,5\% dos entrevistados afirmaram utilizar essa alternativa com maior frequência que as demais.

Ainda que a maioria das viagens motivadas pelo mergulho seja realizada na companhia de amigos ou parentes $(75,6 \%)$, uma parcela considerável destas é feita por indivíduos que viajam sozinhos $(22,5 \%)$. A parcela minoritária restante $(1,9 \%)$ se refere às viagens realizadas apenas na companhia de grupos organizados por escolas e operadoras de mergulho.

Os destinos de mergulho mais visitados do Brasil se concentram próximos aos principais mercados emissores: Baía de Angra, litoral norte do Rio de Janeiro, litoral norte de São Paulo e a Laje de Santos. Também se destacam alguns destinos da região Nordeste, como Fernando de Noronha, litoral de Pernambuco e Abrolhos. A Figura 3 apresenta os percentuais de entrevistados que afirmaram já ter viajado para mergulhar em cada um dos destinos destacados pela pesquisa. 


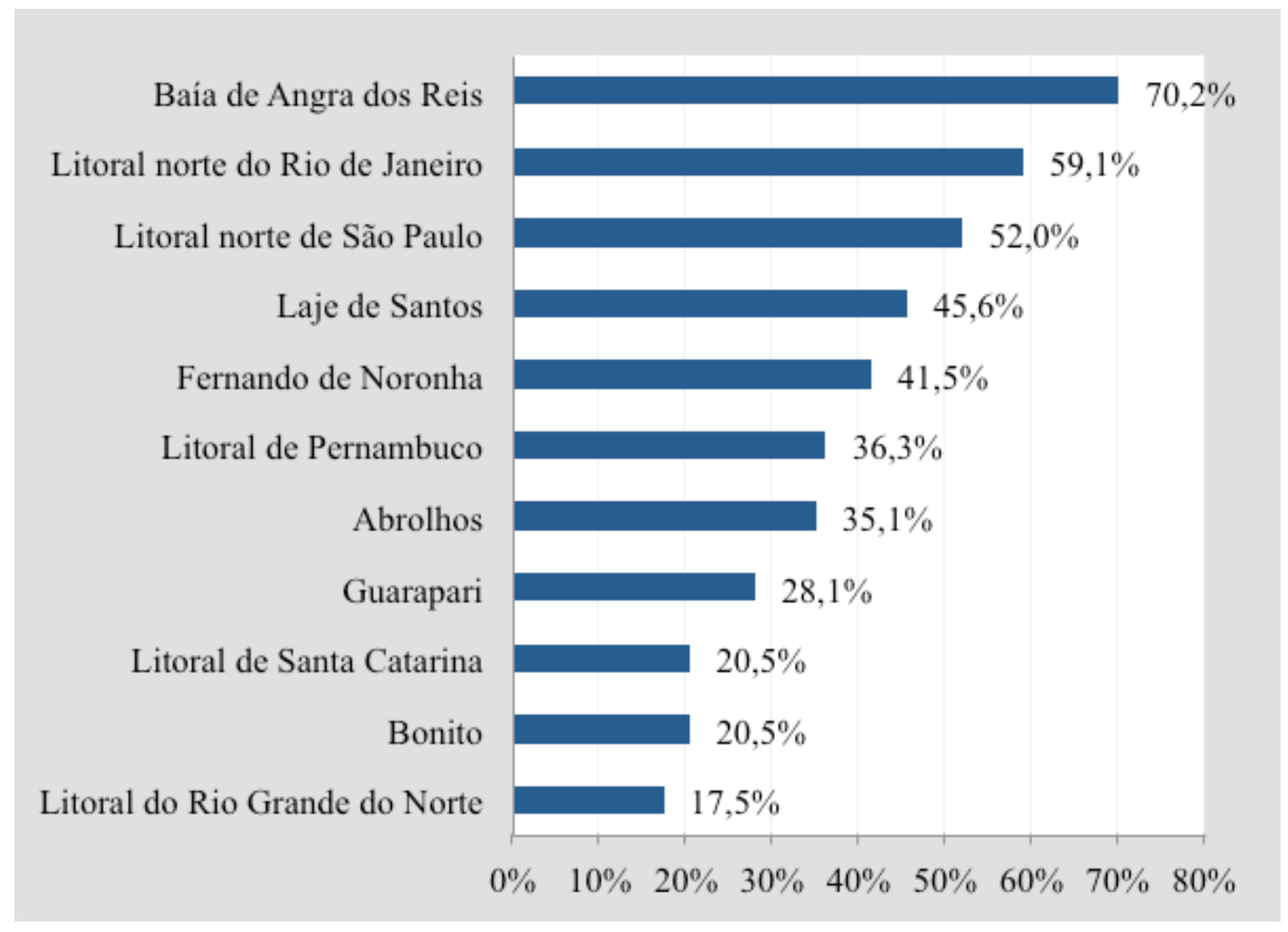

Figura 3 - Destinos nacionais de mergulho mais visitados Fonte: Elaboração própria.

Entre os destinos internacionais, destacam-se aqueles localizados no Caribe. A região já foi visitada com motivação de mergulho por $59,1 \%$ dos entrevistados. Nota-se que esse percentual é apenas comparável aos dois principais destinos nacionais. Em segundo lugar, mas com destaque bastante inferior, estão os Estados Unidos, visitados por cerca de um terço do número que visitou o Caribe (19,9\%). As demais regiões mundialmente reconhecidas pelo mergulho foram visitadas por algo em torno de $10 \%$ dos entrevistados. A Figura 4 apresenta os percentuais de entrevistados que afirmaram ter visitado cada um dos destinos internacionais destacados pela pesquisa. 


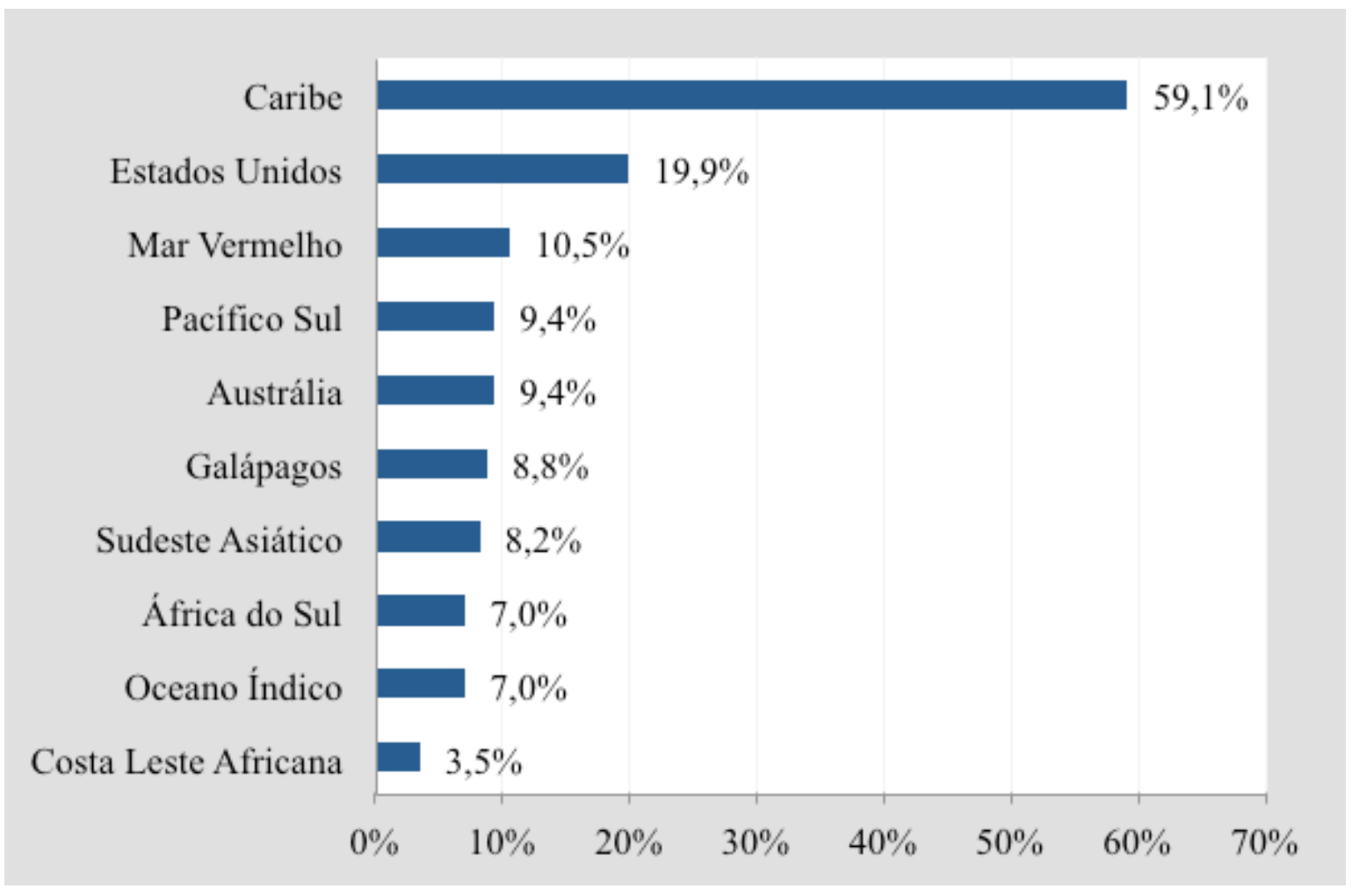

\section{Figura 4 - Destinos internacionais de mergulho mais visitados Fonte: Elaboração própria.}

A maioria dos mergulhadores $(65,6 \%)$ apontou ter preferência por viajar para destinos ainda não visitados. A minoria (22,7\%) prefere retornar para destinos já visitados, enquanto uma parcela ainda menor $(11,7 \%)$ não tem preferência definida nesse quesito. A decisão do destino da viagem é fortemente influenciada pelas características naturais do local, tais como a vida submersa e a geomorfologia dos pontos de mergulho. Apenas 12,3\% dos entrevistados indicaram que esses fatores não têm grande influência na escolha de seus destinos de turismo de mergulho. As características da operação de mergulho, tais como barcos, dive masters e equipamentos, ocupam a segunda posição no ranking de aspectos mais importantes para a decisão do destino de viagem. O custo total da viagem aparece apenas na terceira posição desse ranking, indicando que os turistas de mergulho não se mostram muito sensíveis aos preços de diferentes destinos. A distância do destino também tem influência mediana, fato que reforça a conclusão de que esse público não se preocupa muito com os esforços necessários para chegar ao destino desejado. Por fim, aspectos turísticos comuns, como hospedagem, alimentação e outros atrativos da localidade, têm pequena influência sobre a escolha do destino da viagem de mergulho. A Tabela 1 apresenta as distribuições das opiniões dos entrevistados sobre cada aspecto de acordo com seu grau de importância na escolha do destino da viagem de mergulho. 
Tabela 1 - Importância de diferentes aspectos na escolha do destino de viagem de mergulho

\begin{tabular}{|l|c|c|c|c|c|c|}
\hline \multicolumn{1}{|c|}{ Aspecto } & $\begin{array}{c}\text { Importância } \\
\text { extrema }\end{array}$ & $\begin{array}{c}\text { Grande } \\
\text { importância }\end{array}$ & $\begin{array}{c}\text { Importância } \\
\text { mediana }\end{array}$ & $\begin{array}{c}\text { Alguma } \\
\text { importância }\end{array}$ & $\begin{array}{l}\text { Nenhuma } \\
\text { importância }\end{array}$ & Total \\
\hline $\begin{array}{l}\text { Características } \\
\text { naturais }\end{array}$ & $46,0 \%$ & $41,7 \%$ & $6,1 \%$ & $1,2 \%$ & $4,9 \%$ & $100 \%$ \\
\hline $\begin{array}{l}\text { Operação de } \\
\text { mergulho }\end{array}$ & $31,3 \%$ & $42,9 \%$ & $16,6 \%$ & $4,3 \%$ & $4,9 \%$ & $100 \%$ \\
\hline Serviços turísticos & $10,4 \%$ & $38,0 \%$ & $26,4 \%$ & $17,8 \%$ & $7,4 \%$ & $100 \%$ \\
\hline $\begin{array}{l}\text { Outros atrativos } \\
\text { turísticos }\end{array}$ & $4,9 \%$ & $23,9 \%$ & $33,1 \%$ & $20,9 \%$ & $17,2 \%$ & $100 \%$ \\
\hline Distância & $14,7 \%$ & $37,4 \%$ & $29,4 \%$ & $6,1 \%$ & $12,3 \%$ & $100 \%$ \\
\hline $\begin{array}{l}\text { Custo total da } \\
\text { viagem }\end{array}$ & $32,5 \%$ & $37,4 \%$ & $20,2 \%$ & $4,9 \%$ & $4,9 \%$ & $100 \%$ \\
\hline
\end{tabular}

Fonte: Elaboração própria.

\section{Considerações finais}

O perfil dos mergulhadores pesquisados segue essencialmente aquele encontrado no resto do mundo. Prevalecem os indivíduos do sexo masculino e com idades entre 30 e 50 anos. A grande incidência de mergulhadores com escolaridade e renda altas parece ser ainda mais acentuada na amostra pesquisada. Portanto, os resultados obtidos oferecem indícios de que o mergulho é uma atividade bastante elitizada no Brasil. Do ponto de vista das empresas e destinos turísticos inseridos nesse mercado, a elitização traz oportunidades para a comercialização de serviços de alto valor agregado. Isso significa também um turismo de baixo impacto negativo em comparação com os benefícios econômicos gerados.

O potencial de atração dos destinos está essencialmente atrelado às características naturais dos pontos de mergulho. A preservação ambiental é requisito central para a atratividade. Nesse sentido, o turismo de mergulho não pode ser desenvolvido em locais com características naturais inadequadas. Trata-se de um segmento turístico no qual a oferta original do destino não pode ser substituída por serviços de qualidade, preços baixos ou publicidade. A vantagem competitiva nesse segmento é necessariamente dada a priori. As demais características da oferta turística podem apenas agregar valor a uma oferta original preexistente.

No entanto, isso não significa dizer que os destinos com grande potencial poderão automaticamente se beneficiar do turismo. Políticas públicas de preservação ambiental ineficazes constituem a principal ameaça ao potencial turístico atrativo dos destinos. Uma vez degradado o ambiente submarino, o poder de atração do destino se esvai e não deixa grandes chances de retorno.

É interessante ressaltar também as consequências do perfil alocêntrico dos mergulhadores. Ao buscarem com frequência destinos ainda não visitados, os turistas mergulhadores formam um público com tendência de grande dispersão geográfica. Ao contrário de muitos outros segmentos que tendem a se concentrar em poucos destinos, os mergulhadores parecem fugir dos próprios mergulhadores, e principalmente de outros públicos. Consequentemente, o turismo de mergulho constitui um segmento com grande potencial para distribuição regional da renda, além de dispersar a pressão colocada sobre os recursos 
naturais. Essa característica dos turistas mergulhadores também facilita o surgimento de novos destinos turísticos, desde que estes apresentem potencial natural para a atividade.

Mas o desenvolvimento de destinos turísticos de mergulho pode não ser tão simples quanto parece. A simples propriedade de elementos naturais diferenciados não garante a ocorrência de fluxos turísticos significativos. Sem nenhum trabalho, o destino irá atrair no máximo alguns mergulhadores com perfil explorador aguçado. Na maioria dos casos, é preciso a adoção de estratégias de desenvolvimento que assegurem a preservação ambiental e a oferta de serviços adequados. Conforme discutido, a estrutura do mercado de turismo de mergulho não é simples. As empresas que atuam nesse mercado são altamente especializadas e relativamente desconhecidas do público que não está diretamente envolvido com a atividade. $\mathrm{O}$ comportamento dos turistas de mergulho também é bastante específico. Em particular, deve-se destacar a importância dos relacionamentos sociais dentro desse grupo, fato que torna a comunidade de mergulhadores relativamente pouco acessível a pessoas e empresas de fora. Portanto, as estratégias de marketing do turismo de mergulho devem obrigatoriamente considerar formas de lidar com essa característica do público-alvo, explorando as relações sociais como forma de alcançar o sucesso de mercado.

Esta pesquisa trouxe informações que, de certa forma, abrem muitos caminhos para a realização de estudos futuros. De um lado, pode-se buscar maior detalhamento sobre os turistas de mergulho, incluindo tanto questões relacionadas ao perfil demográfico quanto ao comportamento de viagem e de mergulho. As pesquisas também devem explorar a oferta de serviços desse segmento de mercado. Em particular, parece relevante para o estudo do turismo entender a oferta de pacotes de viagens por parte das escolas de mergulho, já que estas concorrem com agências e operadoras tradicionais, mas estão geralmente excluídas das análises feitas no âmbito da turismologia. O campo de estudo dos impactos sociais, econômicos e ambientais do turismo de mergulho também deve ser mais explorado no Brasil. Por fim, a gestão dos destinos turísticos de mergulho precisa ser melhor debatida no país, especialmente se considerando que, apesar do grande potencial, o Brasil parece longe de figurar entre os principais destinos de turismo de mergulho do mundo.

\section{Referências}

ASAFU-ADJAYE, J.; TAPSUWAN, S. A contingent valuation study of scuba diving benefits: case study in Mu Ko Similan Marine National Park, Thailand. Tourism Management, v. 29, n. 6, p. 1122-1130, 2008.

BRASIL. Ministério do Turismo. Viagem Técnica México: caderno de subsídios. Brasília: Ministério do Turismo, 2005.

BREMMER, J. Into the Deep: World's 50 Best Dive Sites. Disponivel em: 〈http://travel.cnn.com/ explorations/escape/outdoor-adventures/worlds-50-best-dive-sites-895793〉. Acesso em: Jul. 2015.

CATER, C.; CATER, E. Marine environments. In: WEAVER, D. B. (Org.). The Encyclopedia of Ecotourism. Wallingford: CABI, 2001. p. 265-282.

COTTRELL, S. P.; MEISEL, C. Predictors of personal responsibility to protect the marine environment among divers. In: NORTHEASTERN RECREATION RESEARCH SYMPOSIUM, 2003, Newtown Square. Proceedings. Department of Agriculture, Forest Service, Northeastern Research Station, 2004. p. 252261. 
DAVIS, D.; TISDELL, C. Recreational scuba-diving and carrying capacity in marine protected areas. Ocean \& Coastal Management, v. 26, n. 1, p. 19-40, 1995.

DE GROOT, J.; BUSH, S. R. The potential for dive tourism led entrepreneurial marine protected areas in Curacao. Marine Policy, v. 34, n. 5, p. 1051-1059, 2010.

DITTON, R. B. et al. Demographics, attitudes, and reef management preferences of sport divers in offshore Texas waters. ICES Journal of Marine Science: Journal du Conseil, v. 59, p. S186-S191, 2002.

GARROD, B.; GÖSSLING, S. Introduction. In: GARROD, B.; GÖSSLING, S. (Org.). New Frontiers in Marine Tourism: diving experiences, sustainability, management. Oxford: Elsevier, 2008. p. 3-28.

GÖSSLING, S. et al. Diving and global environmental change: a Mauritius case study. In: GARROD, B.; GÖSSLING, S. (Org.). New Frontiers in Marine Tourism: diving experiences, sustainability, management. Oxford: Elsevier, 2008. p. 67-92.

GRAVER, D. Scuba Diving. Champaign: Human Kinetics, 2010.

HALLS, M.; KRESTOVNIKOFF, M. Scuba Diving. Norfolk: Dorling Kindersley, 2006.

IBGE. Sistema IBGE de Recuperação Automática - SIDRA. Disponível em: 〈http://www.sidra.ibge. gov.br/bda/>. Acesso em: Jul. 2015.

INCE, T.; BOWEN, D. Consumer satisfaction and services: insights from dive tourism. Service Industries Journal, v. 31, n. 11, p. 1769-1792, 2011.

LARSON, H. E. A History of Self-Contained Diving and Underwater Swimming. Washington, D. C.: National Academy of Sciences, 1959.

MUNDET, L.; RIBERA, L. Characteristics of divers at a Spanish resort. Tourism Management, v. 22, p. 501, 2001.

MUSA, G.; KADIR, S. L. S. A.; LEE, L. Layang Layang: an empirical study on scuba divers' satisfaction. Tourism in Marine Environments, v. 2, n. 2, p. 89-102, 2006.

O'NEILL, M. A. et al. Diving into service quality - the dive tour operator perspective. Managing Service Quality: An International Journal, v. 10, n. 3, p. 131-140, 2000.

ONG, T. F.; MUSA, G. Examining the influences of experience, personality and attitude on SCUBA divers' underwater behaviour: a structural equation model. Tourism Management, v. 33, n. 6, p. 15211534, 2012.

PADI. PADI Dive Festival. Disponível em: 〈http://www.padifestival.com.br/sobre.aspx〉. Acesso em: Jul. 2015.

. Worldwide Corporate Statistics 2015. 2015b. Disponível em: 〈http://padi.com/scuba-diving/ documents/2015-WW-Statistics/>. Acesso em: Jul. 2015.

PLOG, S. Why destination areas rise and fall in popularity: an update of a Cornell Quarterly classic. The Cornell Hotel and Restaurant Administration Quarterly, v. 42, n. 3, p. 13-24, 2001.

.The power of psychographics and the concept of venturesomeness. Journal of Travel Research, v. 40, n. 3, p. 244-251, 2002.

QUEIROZ NETO, A. C. D. Dive tourism - um mergulho conceitual. In: SEMINÁRIO DE PESQUISA EM TURISMO DO MERCOSUL, VII, 2012, Caxias do Sul. Anais. Caxias do Sul: Universidade de Caxias do Sul, 2012. 
SCHUHMANN, P. W. et al. Willingness to pay to avoid high encounter levels at dive sites in the Caribbean. Tourism in Marine Environments, v. 9, n. 1-2, p. 81-94, 2013.

SCUBA DIVING. 2015 Reader's Choice Awards: Top 100 Gold List. Disponível em: 〈http://www. scubadiving.com/photos/2015-readers-choice-awards-top-100-gold-list>. Acesso em: Jul. 2015.

SCUBA TRAVEL. 100 Top Dive Sites of the World. Disponível em: 〈http://www.scubatravel.co.uk/ topdiveslong.html>. Acesso em: Jul. 2015.

SPORTDIVER. 50 Best Dive Sites in the World. Disponível em: 〈http://www.sportdiver.com/photos/ planets-50-greatest-dives>. Acesso em: Jul. 2015.

STOECKL, N. et al. Live-aboard dive boats in the Great Barrier Reef: Regional economic impact and the relative values of their target marine species. Tourism Economics, v. 16, n. 4, p. 995-1018, 2010.

SZUSTER, B. W.; NEEDHAM, M. D.; MCCLURE, B. P. Scuba diver perceptions and evaluations of crowding underwater. Tourism in Marine Environments, v. 7, n. 3-4, p. 153-165, 2011.

TABATA, R. S. Scuba diving holidays. In: WEILER, B.; HALL, C. M. (Org.). Special interest tourism. London: Belhaven, 1992. p. 171-184.

THAILING, C. E.; DITTON, R. B. Demographics, motivations and participation patterns of sport divers in the Flower Garden Banks National Marine Sanctuary. In: GULF AND CARIBBEAN FISHERIES INSTITUTE, 54, 2003. Proceedings Marathon: Gulf and Caribbean Fisheries Institute, 2003. p. 338-348.

TOWNSEND, C. Dive tourism, sustainable tourism and social responsibility: a growing agenda. In: GARROD, B.; GÖSSLING, S. (Org.). New Frontiers in Marine Tourism: diving experiences, sustainability, management. Oxford: Elsevier, 2008. p. 139-152.

UYARRA, M. C.; WATKINSON, A. R.; COTE, I. M. Managing dive tourism for the sustainable use of coral reefs: validating diver perceptions of attractive site features. Environmental Management, v. 43, n. 1, p. 1-16, 2009.

VANN, R. D.; LANG, M. A. Recreational diving fatalities workshop: summary. In: Recreational Diving Fatalities Workshop, 2010, Durham. Proceedings. Durham: DAN, 2010. p. 5-10.

VASKE, J. J. et al. Measuring variability in encounter norms among scuba divers and snorkelers: an application of the Potential for Conflict Index. Tourism in Marine Environments, v. 9, n. 1-2, p. 69-80, 2013.

WIKIPEDIA. List of Diver Certification Organizations. Disponível em: 〈https://en.wikipedia.org/wiki/ List_of_diver_certification_organizations>. Acesso em: Jul. 2015.

WORLD TourISM ORGANIZATION. Tourism: 2020 vision: global forecast. Madrid: UNWTO, 2007. 